\title{
Research on Patent Distribution of Three Main Chinese Medicinal Materials Such as Panax Notoginseng, Erigeron Breviscapus and Rhizoma Paridis in Yunnan Based on Industrial Chain and Technology Chain
}

\author{
Yaxue Chen \\ Library \\ Yunnan Agriculture University \\ Kunming, Yunnan 650201, China
}

\author{
Chuan Qin \\ 77251 Troops \\ PLA \\ ChongQin, 402260, China
}

\author{
Lina She* \\ Office of Science Research \\ Kunming University \\ Kunming, Yunnan, 650214, China \\ *The corresponding author
}

\begin{abstract}
The herbal medicine planting patents in Yunnan Province are retrieved by means of INCOPAT patent database and the layouts on patent number, industrial chain and technology chain of Panax Notoginseng, Erigeron Breviscapus and Rhizoma Paridis are analyzed in this paper. The layout strategies about the major herbal medicine planting patents in Yunnan are put forward from core technology, high-value peripheral technology, technology standard and regional development. The result of the research shows that to Panax Notoginseng, the core technology is the important study direction and the high-value peripheral technology must be actively arranged; to Erigeron Breviscapus, the patent layout must be guided by planting technology standard.
\end{abstract}

Keywords-pseudo-ginseng; erigeron breviscapus; paris polyphylla; patent layout; industrial chain; technology chain

\section{INTRODUCTION}

As early as May 2001, Yunnan has been approved by the Ministry of Science and Technology as the national base of modern science and technology industry of traditional Chinese medicine (Yunnan). Pharmaceutical industry of Chinese patent medicine has also developed rapidly. Yunnan has established pseudo-ginseng, Erigeron breviscapus, Gastrodia elata, Baiyao and other well-known brand series of cloud medicine. The development of pharmaceutical industry has further promoted the development of Chinese traditional medicine planting industry. In recent years, the state attaches great importance to the development of traditional Chinese medicine industry. It has issued a series of important documents, such as the Outline of Strategic Planning for the Development of

Fund Project: 2016 Yunnan University Agricultural Science Socia Science Youth Project "Yunnan Chinese Herbal Medicine Planting Technology Patent Layout Strategy Research", Project No: 2016SK14
Traditional Chinese Medicine (2016-2030) and the Outline of "Healthy China 2030", and has incorporated the development of traditional Chinese medicine into the national development strategy. Traditional Chinese medicine industry is an important part of modern agriculture, biomedicine and health industry with Yunnan plateau characteristics. Among them, pseudo-ginseng and paris polyphylla belong to genuine medicinal materials, with output value of more than 1 billion yuan, which is the highest yield medicinal materials in Yunnan.[1] In addition, Erigeron breviscapus accounts for $95 \%$ of the total output in China.[2].

The author selected three representative patents in Yunnan in recent years and analyzed them systematically. It was found that most of the planting enterprises lacked systematic patent layout to maintain their competitive advantage. At present, multinational enterprises are using patent distribution strategy to divide up and occupy the Chinese market. Faced with the severe patent competition situation, many documents issued jointly by the State Council, the State Intellectual Property Office and relevant ministries and commissions all put forward and emphasized the need to "develop patent distribution, form a batch of patent portfolios in key technical fields, and build patent reserves to support industrial development and enhance the competitiveness of enterprises" .[3]Based on comprehensive consideration of industry, market, technology, law and other factors, the planting industry of Chinese medicinal materials urgently needs targeted and strategic patent planning and deployment from the aspects of technology field, patent application area, application type and application quantity, so as to maximize the value of patents. In view of this, this study searched the 
related planting patents of pseudo-ginseng, Erigeron breviscapus and paris polyphylla in Yunnan through INCOPAT patent database (the date of retrieval is April 30, 2017). Through the method of patent analysis, this paper grasps the layout characteristics of three kinds of traditional Chinese medicine planting industry, puts forward the patent layout strategy which is helpful to the development of enterprises, and provides important intellectual property information support for the development of Yunnan traditional Chinese medicine planting industry.

\section{ANALYSIS OF PATENT LAYOUT OF MAIN CHINESE} Medicinal Material Planting TECHNOLOGIES IN YUNNAN

\section{A. Analysis of Patent Quantity and Quality Layout}

\section{1) Patent Quality Analysis}

Incopat database is used to measure the quality of patents. Specific technical indicators include three indicators: technical stability, technological advancement and scope of protection. Each indicator is composed of several detailed indicators (see Table 1). On this basis, according to the influence of each index on the value, the influencing factors of each index are set to make the weight of each index more reasonable.

TABLE I. Shared VALUe Index CONTENTS

\begin{tabular}{|c|c|}
\hline Index & Partial reference details indicators \\
\hline $\begin{array}{l}\text { Technical } \\
\text { stability }\end{array}$ & $\begin{array}{l}\text { (1) Effective invention patent, good stability } \\
\text { (2) No lawsuit } \\
\text { (3) No pledge } \\
\text { (4) No review } \\
\text { (5) Not declared invalid declaration }\end{array}$ \\
\hline $\begin{array}{l}\text { Technological } \\
\text { advancement }\end{array}$ & $\begin{array}{l}\text { (1) Cited } 5 \text { times } \\
\text { (2) Involves } 1 \text { IPC team, the application field is generally } \\
\text { (3) At least } 4 \text { people are invested in R\&D personnel } \\
\text { (4) No license has occurred } \\
\text { (5) A transfer occurred }\end{array}$ \\
\hline $\begin{array}{l}\text { Scope of } \\
\text { protection }\end{array}$ & $\begin{array}{l}\text { (1) There are at least } 3 \text { claims } \\
\text { (2) Within the validity period }\end{array}$ \\
\hline
\end{tabular}

Shared value is divided into 1-10 levels. The value of patents increases step by step from level 1 to 10 . The higher the series, the greater the value of patents, the higher the value of patents, the higher the quality of patents. Table 2 below lists the number of pseudo-ginseng, Erigeron breviscapus, paris polyphylla planting technology patents in grades 7-10, 4-6 and 1-3 and their percentage of total patents(The default patent level $7-10$ is of high quality). It can be seen that there are fewer high-quality patents for pseudo-ginseng and paris polyphylla 7-10, and there are more patents for mediumquality patents 4-6. Although the number of applications for erigeron breviscapus is small, the number of patents of 7-10 is more. The patent quality of erigeron breviscapus is 2-4 times higher than that of pseudo-ginseng and paris polyphylla.
TABLE II. COMPARISON OF PATENT VALUE OF DIFFERENT SHARING VALUE OF PSEUDO-GINSENG, ERIGERON BREVISCAPUS AND PARIS POLYPHYLLA

\begin{tabular}{|l|c|c|c|c|c|}
\hline & $\begin{array}{c}\text { Level } \\
\mathbf{7 - 1 0} \\
\text { (piece) }\end{array}$ & $\begin{array}{c}\text { Level } \\
\mathbf{4 - 6} \\
\text { (piece) }\end{array}$ & $\begin{array}{c}\text { Level } \\
\mathbf{1 - 3} \\
\text { (piece) }\end{array}$ & $\begin{array}{c}\text { Total } \\
\text { number }\end{array}$ & $\begin{array}{c}\text { Number of } \\
\text { patents in total } \\
\text { patents of level } \\
\mathbf{7 - 1 0}(\%)\end{array}$ \\
\hline $\begin{array}{l}\text { Pseudo- } \\
\text { ginseng }\end{array}$ & 27 & 182 & 29 & 238 & $11 \%$ \\
\hline $\begin{array}{l}\text { Erigeron } \\
\text { breviscapus }\end{array}$ & 8 & 6 & 0 & 14 & $57 \%$ \\
\hline $\begin{array}{l}\text { Paris } \\
\text { polyphylla }\end{array}$ & 16 & 103 & 6 & 125 & $19 \%$ \\
\hline
\end{tabular}

\section{2) Effective patent ratio}

Another indicator of patent quality is the ratio of effective patents. Table 3 shows a comparison of the number of patents invented by major applicants for pseudo-ginseng, Erigeron breviscapus and Paris polyphylla in the traditional planting field (A01G). It shows that Honghe Qianshan Bioengineering Co., Ltd. has a relatively small number of invention patents in the field of $\mathrm{A} 01 \mathrm{G}$, but its effective patent ratio is high, its patent quality is high, and its patent stability is strong. In contrast, most of the invention patents of Wenshan Miaoxiang pseudo-ginseng Technology Co., Ltd. in the field of A01G are less valid. Yimen Yuanyuan Forest and Agricultural Products Development Co., Ltd. has fewer invention patents in the field of $\mathrm{A} 01 \mathrm{G}$ and no valid patents. The result of this data analysis is consistent with the analysis of shared value.

TABLE III. NUMBER OF INVENTION PATENTS IN THE FIELD OF A01G BY THE MAIN COMPANIES (APPLICANTS) OF PSEUDO-GINSENG, ERIGERON BREVISCAPUS, AND PARIS POLYPHYLLA

\begin{tabular}{|l|c|c|c|}
\hline \multicolumn{1}{|c|}{ Company Name } & $\begin{array}{c}\text { A01G invention } \\
\text { patent quantity } \\
\text { (piece) }\end{array}$ & $\begin{array}{c}\text { Right } \\
\text { (piece) }\end{array}$ & $\begin{array}{c}\text { Effective } \\
\text { patent } \\
\text { ratio }\end{array}$ \\
\hline $\begin{array}{l}\text { Wenshan Miao County } \\
\text { Pseudo-ginseng Technology } \\
\text { Co., Ltd. (pseudo-ginseng) }\end{array}$ & 43 & 3 & $6.9 \%$ \\
\hline $\begin{array}{l}\text { Honghe Qianshan Biological } \\
\text { Engineering Co., Ltd. } \\
\text { (erigeron breviscapus) }\end{array}$ & 5 & 4 & $80 \%$ \\
\hline $\begin{array}{l}\text { Yimen Yuanyuanlin } \\
\text { Agricultural Products } \\
\text { Development Co., Ltd. (paris } \\
\text { polyphylla) }\end{array}$ & 2 & 0 & 0 \\
\hline
\end{tabular}

From the two indicators of shared value and effective patent ratio, it can be found that most enterprises applying for patents for planting Chinese medicinal materials adopt the layout idea of winning by the number of patents. A large number of patent applications or acquisition is the most important consideration of enterprises in patent application. But blind and lack of forward-looking patent applications will not only waste a lot of human, material and financial resources but also may lose the best layout opportunities.

\section{B. Analysis of Industrial Chain Layout}

The industrial chain of Chinese medicinal materials is a chain structure formed around the main products of Chinese medicinal materials. In this structure, taking modern Chinese medicine manufacturing as the core, the value chain of Chinese medicine industry is formed by concentrating on the links of medicinal material planting, drug research and development, ingredient extraction and drug manufacturing. 
Patents for medicinal plant are upstream patents in the whole industrial chain. As all pharmaceutical products inevitably use basic raw materials, basic raw materials are an unavoidable aspect of any product. Therefore, the technological innovation of planting industry has a wide market influence. Lack of these planting patents, on the contrary, it is easy to form a technological gap and bring opportunities to competitors. At the same time, the implementation of these patented technologies can not only ensure the authenticity of medicinal plants from the source, but also ensure the stability of product quality. In addition to the patent for drug research and development, some large domestic pharmaceutical enterprises such as Tianshili Group also include the cultivation method of APIs, such as "a pseudo-ginseng soilless cultivation method CN106613855A" and "a pseudo-ginseng Soilless Seedling cultivation method CN106665312A". In Yunnan Province, Yunnan Baiyao Group also has patents related to planting, such as "a method of Yunnan Paris polyphylla seed nursery CN104541833A".

This study found that some planting enterprises in Yunnan Province also adopted the way of patent distribution around the industrial chain of Chinese medicinal materials, such as Honghe Qianshan Bioengineering Co., Ltd., which has the largest number of patents in the field of Erigeron breviscapus. In addition to the patents related to planting, other patents cover the preparation of APIs related to Erigeron breviscapus and the development of health products related to Erigeron breviscapus (see table 4). This shows that the company not only focuses on the upstream planting field of Erigeron breviscapus, but also focuses more on the downstream production of Erigeron breviscapus. This shows that the company not only focuses on the upstream planting field of Erigeron breviscapus, but also focuses more on the downstream production of Erigeron breviscapus. The biggest advantage of the layout around the industrial chain is that no matter which link competitors compete from upstream to downstream, there are unavoidable patent barriers, which undoubtedly create more obstacles for competitors.

TABLE IV. RED RIVER QIANSHAN BIOLOGICAL ENGINEERING Co., LTD. ERIGERON BREVISCAPUS INDUSTRY PATENT LAYOUT

\begin{tabular}{|l|l|}
\hline \multicolumn{1}{|c|}{$\begin{array}{c}\text { Patent layout } \\
\text { field }\end{array}$} & \multicolumn{1}{c|}{ Patent name } \\
\hline Planting & $\begin{array}{l}\text { Erigeron breviscapus greenhouse continuous cropping } \\
\text { method CN103650877A } \\
\text { Floating seedling method of erigeron breviscapus CN } \\
103688742 \mathrm{~A}\end{array}$ \\
\hline $\begin{array}{l}\text { Preparation of } \\
\text { raw materials }\end{array}$ & $\begin{array}{l}\text { Method for preparing erigeron breviscapus substance raw } \\
\text { Preparion method of high-purity erigeron breviscapus } \\
\text { raw material medicine CN 102351929A } \\
\text { Method for extracting erigeron breviscapus from fresh } \\
\text { erigeron breviscapus CN 100425616C }\end{array}$ \\
\hline $\begin{array}{l}\text { Health product } \\
\text { development }\end{array}$ & $\begin{array}{l}\text { Erigeron breviscapus health wine and preparation method } \\
\text { thereof CN 101307283A }\end{array}$ \\
\hline
\end{tabular}

From the analysis of the applicants, it is found that all the patents of the company are applied independently and lack of joint application with other units. From the analysis of the applicants, it is found that all the patents of the company are applied independently and lack of joint application with other units. Therefore, the layout enterprises should have a long- term vision and strengthen the cooperation with related enterprises in the industrial chain. For example, planting enterprises and pharmaceutical enterprises should solve technical problems through joint technical research and make joint applications; through the establishment of R\&D methods complementary to technological advantages between competitors in the same industry, focusing effect can be formed geographically, which is conducive to promoting the technological development of the industry; planting enterprises should actively mobilize the enthusiasm of farmers to develop, create and use new technologies to plant Chinese medicinal materials. Joint applications should be made between industries, farmers and planting cooperatives to form a cooperative coordination mechanism, which constitutes the group competitive advantage of Chinese medicinal materials planting industry.

\section{Analysis of Technology Chain Layout}

Technological chain is an industrial cluster chain with some internal links.[4]It includes not only the horizontal analysis of matching technology based on the same technological link of the industrial chain, but also the vertical analysis of matching technology based on different technological links upstream and downstream of the industrial chain.[5]From this definition, it can be found that the technology chain of traditional Chinese medicine planting includes not only the vertical technology chain composed of different technical links such as breeding, seedling raising, fertilization, pest control and field management methods of traditional Chinese medicine but also the horizontal technology chain composed of technical branches under a specific technical link. Whether to adopt vertical or horizontal technology layout should be determined according to the development trend of the enterprise itself and the position of the enterprise in the industry.

Wenshan Miaoxiang Pseudo-ginseng Technology Co., Ltd. started early in the field of pseudo-ginseng, with a large number of patents, occupying a leading position in the industry. As a result, the company has adopted the main layout of vertical technology chain (see Fig. 1). From pseudoginseng's seedling raising, planting, fertilization to pseudoginseng's transplanting, pest control and irrigation, there are patent distributions to protect the proprietary methods of different branches of technology. At the same time, patents for utility models have also been applied for some supporting facilities related to pseudo-ginseng cultivation, such as "a pseudo-ginseng irrigation system" and "invention patents and utility patents", forming a patent layout of "invention + utility model". 


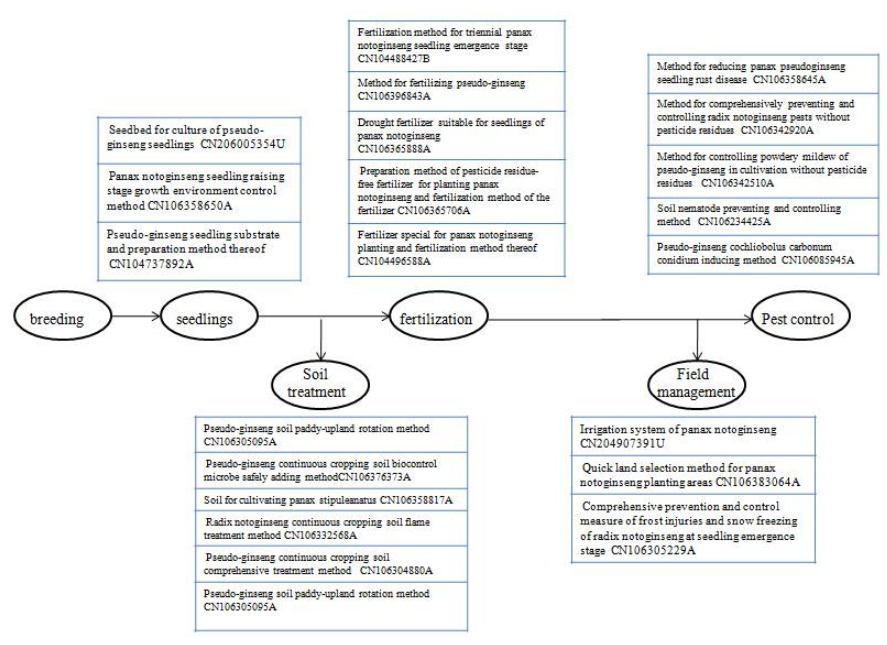

Fig. 1. Wenshan Miaoxiang pseudo-ginseng Technology Co., Ltd. pseudoginseng planting patent vertical technology chain layout

There are also enterprises that layout their patents in the way of horizontal technology chains, that is, for specific technology applications under a technology branch. For example, the patent distribution of Yunnan Tiantian Network Technology Co., Ltd. is closely related to pest control (see Fig. 2 ). Patent technology includes the prevention and control of pseudo-ginseng diseases (anthracnose, rot, blight, virus disease, root-knot nematode disease, powdery mildew, rust, bacterial wilt, root rot, gray mold, sudden collapse disease, etc.) and pseudo-ginseng insect pests (Landrace tiger, leaf rollers, Spodoptera litura, aphids, pseudo-seng thrips, etc.). It can be seen that the company adopted a differentiated competition mode, avoided the vertical technology chain layout mode of Wenshan Miaoxiang Pseudo-ginseng Technology Co., Ltd. and focused on the key technology point, pest control, through the horizontal technology chain layout to make the layout range very concentrated.

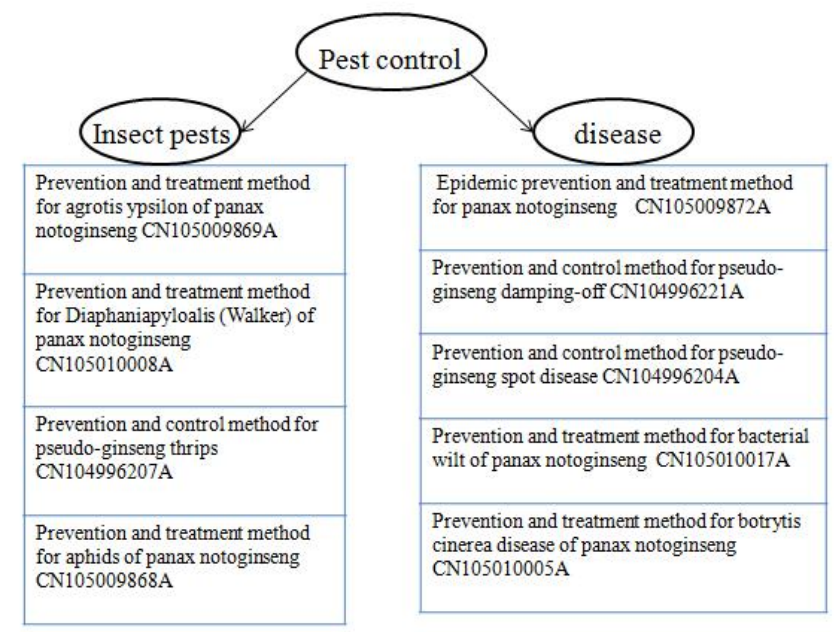

Fig. 2. Patent layout of pseudo-ginseng planting patent horizontal technology chain in Yunnan Tiantian Network Technology Co., Ltd.

Through the analysis of the above patent quantity layout, industrial chain layout and technology chain layout, it can be seen that the current distribution of pseudo-ginseng, Erigeron breviscapus, Paris polyphylla planting patents presents the following characteristics: patent distribution centered on the number of patent applications is still the layout idea of most enterprises; enterprises that carry out patent distribution through the industry chain of traditional Chinese medicine have a long-term vision, but they still need to reach consensus with downstream enterprises and carry out multi-level and multi-level technical cooperation; patent distribution through TCM planting technology chain can be divided into horizontal technology chain and vertical technology chain, which shows that enterprises have begun to carry out targeted market layout, and the differentiation competition is obvious.

\section{ANALYSIS OF PATENT LAYOUT STRATEGIES FOR MAJOR CHINESE MEDICINAL MATERIALS Planting IN YUNNAN}

The patent layout is not simply a superposition of the number of patents. As a commercial means or strategic reserve, based on limited resources and specific business needs, patent layout must be strategic.[6] This strategy is embodied in the overall design of layout technology and flexible selection of different layout methods from the perspective of protection and competition, taking into account the dynamic development of technology, industrial environment, competitive environment and other factors. This study proposes the following four patent distribution strategies from the perspective of Chinese herbal medicine planting industry.

\section{A. Protective Design Architecture: Focusing on Core Technology}

Traditional Chinese medicine planting industry is a traditional industry, showing the characteristics of slow technological upgrading, but the amount of patent applications in this field is relatively large. This is because the field has a low starting point and is easy to enter. A large number of innovators have carried out large-scale and multi-angle improvement research on the existing basis, and have obtained more improved research results. The research focuses on the application of conventional cultivation methods to solve the problem of endangered wild medicinal plants. Taking pseudoginseng as an example, the continuous cropping disorder caused by plant-ginseng has led to the gradual tension of suitable land in traditional production areas, and the planting area has been extended, and the authenticity of pseudoginseng medicinal materials is gradually difficult to be guaranteed. Therefore, most of the patented technologies are developed around solving the problem of continuous cropping. The main solution is to carry out the three aspects of soil treatment, mitigation of self-toxic injury and disease prevention. In the practical application of the pseudo-ginseng planting field, there is still a lack of core technology patents that can completely solve the problem of pseudo-ginseng continuous cropping.

In addition, in the field of traditional Chinese medicine planting, high-quality germplasm resources are the lifeblood of planting development. Transgenic breeding has been applied in the field of breeding because of its short cycle, strong pertinence and the ability to expand the available 
genetic resources. At present, the hotspot of transgenic technology in the world is to transfer good target genes into medicinal plants for the production of drugs, in order to obtain higher yield, quality, disease resistance, insect resistance and herbicide resistance varieties.[7] Most of Monsanto's breeding patents involve GM technology. On the contrary, there are few patent documents on the breeding of main Chinese medicinal materials in Yunnan, which are related to GM technology. The representative patent is only one breeding patent related to Erigeron breviscapus: "A method of establishing an efficient transfection system of Erigeron breviscapus mediated by Agrobacterium tumefaciens, CN 106119276A". This method can cultivate new Erigeron breviscapus through agrobacterium transfection system, which means that it can break through the genetic barrier of Erigeron breviscapus and obtain new varieties which are difficult to produce by traditional breeding methods. It is an example of the application of genetically modified technology in Erigeron breviscapus breeding field. In the field of pseudo-ginseng and paris polyphylla planting, no relevant transgenic patent technology has been seen. This result supports the highest value data of the erigeron breviscapus in the above-mentioned 2.1.1.

It can be seen from the above that the current patents of Chinese medicinal materials lack the lead of core technology. Therefore, the Chinese herbal medicine planting industry should pay attention to the current technical difficulties and key points at the level of technology research and development, such as genetically modified breeding, tissue culture and so on. Combining with industry chain and technology chain, we should form the key layout direction around core technology, or select high-value technology to form core patents with strong protection scope in advance by using the value screening method in the two sections mentioned above, and lead the whole patent layout with core technology.

\section{B. Design and Maintenance Based on Competition - Layout Peripheral High-Value Patent}

In addition to the core patent technology, we should carry out all-round periphery defense of the entire patent layout through some high-value peripheral patents, so we should pay close attention to the emerging research directions. For example, the quality of Chinese medicinal materials is directly determined by the active ingredients of Chinese medicinal materials. The cultivation of Chinese medicinal materials with high content of active ingredients through improved planting measures can not only alleviate the pressure of shortage of Chinese medicinal materials resources, but also be an important way to improve the quality of Chinese medicinal materials. Patent "A method for increasing the content of pseudo-ginseng saponin R1 in pseudo-ginseng CN105009917B" sprays the leaves of pseudo-ginseng with a salicylic acid solution before harvesting in pseudo-ginseng to stimulate and induce the expression of the pseudo-ginseng saponin R1 biosynthesis functional gene in pseudo-ginseng, broke the rate-limiting step in the synthesis of pseudo-ginseng saponin R1, thereby accumulating a large amount of pseudoginseng saponin R1 in a short time. Patent "Method for applying molybdenum fertilizer to improve active ingredient of erigeron breviscapus CN105359803A" uses a method of spraying a trace element of molybdenum fertilizer on the leaves to increase the content of erigeron breviscapus active ingredients stellate and caffeate.This kind of patented technology that enhances the active ingredients through planting techniques has broad practical application prospects. Relevant planting companies can apply for a large number of peripheral high-value patents around the technologies and methods realized by these patents, intercepting the path that competitors may invent and create, and protect the original innovation of the enterprise through high-value peripheral patents.

\section{Based on Optimized Design Means - Strengthen Patent Technology Layout around Existing Technology Standards}

Patent standardization has become the mainstream trend of international technology competition, especially in the field of high-tech applications. It has become a new tool for high-tech enterprises to maintain competitive advantages and gain monopoly benefits by incorporating patented technology into enterprise technical standards and further upgrading enterprise technical standards to industry standards, national standards and even international standards. However, in the field of traditional Chinese medicine planting, the technology content of industry is low and planting schemes are diversified. In addition, the current level of traditional Chinese medicine planting in Yunnan Province and even the whole country is not high, the quality of related patents is low, and the number of patents is insufficient. It is difficult to carry out patent distribution through standardization of patent technology, but achievements have been made. Some universities and enterprises outside the province, such as Zhejiang Agricultural and Forestry University, Guizhou Normal University, Guizhou Yilong Biotechnology Co., Ltd. and Anhui Shengnong Biotechnology Co., Ltd., have taken the lead in formulating local standards for Dendrobium formulate "Dendrobium candidum cultivation technology regulations" (LY/T 25472015), and "Dendrobium candidum hybrid breeding technical regulations" (LY/T 2698-2016).

In recent years, Wenshan pseudo-ginseng, Honghe erigeron breviscapus, Yulong Yunnan paris polyphylla, etc. have applied for the protection of national geographical indication products, and related enterprises in Yunnan Province have also participated in the formulation of national standards. For example, the Wenshan pseudo-ginseng Institute of Science and Technology participated in the formulation of the pseudo-ginseng standard for geographical indication products (GB/T 19086-2008); Honghe Qianshan Bioengineering Co., Ltd. participated in the drafting of Ergeron breviscapus standard for geographical indication products (GB/T 23404-2009); in 2016, Yulong Yunnan Paris polyphylla officially passed the National Geographic Indicators Product Certification, indicating that some enterprises have standard consciousness and positively construct layout standards. Therefore, such enterprises that have participated in the formulation and even revision of standards should make full use of their advantages. On the one hand, through the patented way of standard technology, on the basis of research and analysis of existing standards, the level 
of technical standards is constantly improved; on the other hand, the development of standards is greatly guided by the area, so as to fill in the gaps of existing standards with proprietary patents as far as possible. In contrast, the pace of these Chinese herbal medicine planting enterprises in Yunnan Province is slightly slow. Therefore, local standards should be formulated as soon as possible to provide the basis for the declaration and protection of national geographical indications products.

\section{Design Region Based on Development: Actively Layout Foreign Market}

As early as 2009, the State Intellectual Property Office (SIPO) mentioned in its report "Current Situation and Development Trend of Patented Technology for Medicinal Plant Breeding and Cultivation" that although China has unique advantages in the research of medicinal plants. However, in the international market, patent protection shows the characteristics of focusing only on domestic applications and low international market share.[8] Now nearly ten years have passed. According to the situation of three kinds of traditional Chinese medicines studied in this subject, the planting enterprises still lack the measures of patent distribution to the international market. One reason is that enterprises do not know the process of applying for patents in the international market, and they are still confused about which country to apply for patents and how to apply for patents; on the other hand, enterprises still lack confidence in their own patent level, especially in the premise that it takes a lot of material and financial resources to allocate patents to foreign markets, and even less courage to push patents into the international market.

At present, foreign enterprises have begun to actively distribute China's domestic patent market in an attempt to monopolize China's traditional Chinese medicine resources from the source. For example, as early as 1991, Japan's largest manufacturer of Chinese traditional medicine, Jinmura, a Japanese company, established a branch in China, specializing in the processing, cultivation and production of Chinese traditional medicines to provide raw materials for Jinmura, a Japanese company. The company applied for the patents of cultivation methods of Polyporus umbellatus (CN 101080989B) in 2007, licorice cultivation methods (CN101617597B) in 2008, ginseng cultivation methods (CN103153039B) in 2011, Poria cocos cultivation methods (CN 104284578A) in 2014, a patent for the symbiotic method of Polyporus umbellatus and Armillaria mellea species and the cultivation method of Polyporus umbellatus using this method (CN105379554A) and a patent for the cultivation method of Ginseng (CN106413380A) in 2015.

Therefore, under such an international situation, pseudoginseng, Erigeron breviscapus and Paris polyphylla should plan their overseas distribution as soon as possible. In order to seize the first chance in the future market competition, they should determine the core patents applied for overseas through patent screening and sorting, and select the target market of overseas distribution.

\section{CONCLUSIONS}

Patent distribution is the key in the competition of the future medicinal plant industry. Patent quantity distribution, industry chain layout and technology chain layout are the typical parts of the analysis of pseudo-ginseng, Erigeron breviscapus, Paris polyphylla patent distribution of Yunnan's main traditional Chinese medicines, which have representative reference value for most planting enterprises. Whether enterprises adopt the layout mode of industrial chain of traditional Chinese medicines or the layout mode of planting technology chain of traditional Chinese medicines, they must combine their own development characteristics and abandon the view that the number of patents is paramount and plan the patent application and patent portfolio by taking into account the factors of technology development, industrial environment and competitive environment.

The strategy of patent layout is ever-changing. This paper only puts forward the overall strategy of patent distribution from the perspective of Chinese herbal medicine planting industry: that is, to focus on the core technology, to lay out high-value patents around the periphery, to carry out standard patented distribution around existing standards, and positively lay out the strategy of foreign markets in the region. However, the degree of technological innovation activities of each enterprise is different. In practical application, it is necessary to determine its own patent layout strategy closely around the technological competitive advantage of the enterprise. In terms of patent distribution strategies for different categories of three main medicinal materials, it is necessary to take into account the current status of fine variety breeding and related technical standards, as well as the low quality of pseudo-ginseng and Paris polyphylla patents. It is suggested that pseudo-ginseng planting should focus on core technology and positively distribute foreign markets; Erigeron breviscapus planting should focus on high-value peripheral technology; Paris polyphylla planting should be guided by planting technology standards. Only through careful planning and overall arrangement of patent distribution can we expand the interest chain and increase the added value for R\&D on the basis of guaranteeing the market value of traditional Chinese medicines.

\section{REFERENCES}

[1] Notice of the State Council and the State Council on Printing and Distributing the Outline of Chinese Medicine Development Strategy (2016-2030): Guofa [2016] 15 [DB/OL].[2016-0222].http://www.gov .cn/zhengce/content/201602/26/content 5046678.htm

[2] Kunming Daily. Four Erigeron Breviscapus Varieties in Yunnan were Examined by Experts. [EB/OL]. [2018-05-24] Http://society.yunnan.cn/html/2018-05/24/content_5219579.htm

[3] Notice of the General Office of the State Council and the General Office of the State Council on Forwarding the Implementation of the National IP Strategy Action Plan (2014-2020) by the Intellectual Property Office and other units, Guo Ban Fa [2014] No. 64 [EB/OL]. Http://www.gov.cn/zhengce/content/2015-01/04/content_9375.htm

[4] Yuan Deyu. Industrial Technology Industry[J]. Journal of Northeastern University: Social Science Edition, 2000(1): 22-25

[5] Wang Invent, Mao Jianqi. Research on Technology Chain, Industrial Technology Chain and Industrial Upgrading-Taking China's 
Semiconductor Lighting Industry as an Example[J]. Research and Development Management, 2010,22(3):19-28.

[6] Ma Tianqi et al. Patent Layout [M]. Beijing: Intellectual Property Publishing House, 2016. Page 7.
[7] China Intellectual Property Research Association. Report on the status and development trend of patent technology in various industries 20092010[M]. Beijing: Intellectual Property Publishing House, 2010. p. 22.

[8] China Intellectual Property Research Association. Report on the status and development trend of patent technology in various industries 20092010[M]. Beijing: Intellectual Property Publishing House, 2010. p.26. 